\title{
Correction to: Surface Downward Longwave Radiation Retrieval Algorithm for GEO-KOMPSAT-2A/AMI
}

\author{
Seo-Hee Ahn ${ }^{1,3} \cdot$ Kyu-Tae Lee ${ }^{1,2} \cdot$ Se-Hun Rim ${ }^{1,2} \cdot$ II-Sung Zo ${ }^{2} \cdot$ Bu-Yo Kim ${ }^{1,2}$ \\ Published online: 12 September 2018 \\ (C) Korean Meteorological Society and Springer Nature B.V. 2018
}

Correction to: Asia-Pac. J. Atmos. Sci., 54(2), 237-251, 2018

https://doi.org/10.1007/s13143-018-0007-1

In the original version of this article the necessary acknowledgements were unfortunately missing. The correct acknowledgements are given below.

Acknowledgements This work was supported by "Development of Radiation/Aerosol Algorithms" project, funded by ETRI, which is a subproject of "Development of Geostationary Meteorological Satellite Ground Segment (NMSC-2018-01)" program funded by NMSC (National Meteorological Satellite Center) of KMA (Korea Meteorological Administration).

The online version of the original article can be found at https://doi.org/ 10.1007/s13143-018-0007-1

Kyu-Tae Lee

ktlee@gwnu.ac.kr

1 Department of Atmospheric and Environmental Sciences, Gangneung-Wonju National University, Gangneung, Korea

2 Research Institute for Radiation-Satellite, Gangneung-Wonju National University, Gangneung, Korea

3 Division of Polar Climate Sciences, Korea Polar Research Institute, Incheon, Korea 